\title{
Gonadotroph pituitary macroadenoma inducing ovarian hyperstimulation syndrome: successful response to octreotide therapy
}

\author{
Olga Karapanou, Marinella Tzanela, Nikolaos Tamouridis, Stylianos Tsagarakis \\ Department of Endocrinology, Diabetes and Metabolism, “Evangelismos" Hospital, Athens, Greece
}

\begin{abstract}
We report a young woman with spontaneous ovarian hyperstimulation syndrome (OHSS), headaches, visual field defect and pituitary macroadenoma. She underwent transsphenoidal surgery with remission of OHSS. Immunohistochemical staining was positive for $\beta$-FSH and $\beta$-LH. Recurrence occurred after four years. The patient was treated with octreotide administration and conventional radiation therapy. Octreotide was effective in normalizing estradiol levels and resolving OHSS. This is a rare description of octreotide administration as an effective treatment modality of OHSS caused by gonadotropin-secreting pituitary adenomas.
\end{abstract}

Key words: Gonadotroph macroadenoma, Octreotide, Ovarian hyperstimulation syndrome

\section{INTRODUCTION}

Gonadotroph adenomas, as detected by immunohistochemistry, represent approximately $40 \%$ of pituitary macroadenomas. ${ }^{1}$ In their vast majority, these tumors secrete biologically inactive gonadotropin monomer subunits instead of the intact bioactive heterodimers and thus they do not cause a recognizable clinical syndrome. ${ }^{2}$ Exceptionally, functional gonadotrophin releasing pituitary adenomas have been described with clinical manifestations varying from precocious puberty to ovarian hyperstimulation syndrome (OHSS) in premenopausal women ${ }^{3,4}$ and testicular enlargement in men. ${ }^{5}$ Experience in medical

\section{Address for correspondence:}

Olga Karapanou, M.D., 45-47 Ipsilantou St, 10676 Athens,

Greece, Tel.: +30 210 7201825, Fax: +30213 2041828,

e-mail: olgakarapanou@yahoo.com

Received 07-12-11, Revised 06-02-12, Accepted 21-02-12 management of functional gonadotrophin-secreting pituitary tumors is limited. Herein, we present a case of OHSS secondary to a functional gonadotrophin releasing pituitary adenoma, successfully responding to octreotide administration.

\section{CASE REPORT}

A 37-year old woman presented to the endocrine department due to spontaneous vaginal spotting and headaches. She had regular menses since the age of 13 years. Six months before admission she developed secondary amenorrhea and fronto-parietal headaches. One month before admission she observed spontaneous vaginal spotting. She had one full-term gestation 12 years previously and took no medication.

Physical examination was unremarkable. Visual acuity was intact and visual fields assessed by Goldman 
perimetry showed a small upper temporal defect. Routine laboratory profile was within normal range and pregnancy test was negative. Her estradiol $\left(\mathrm{E}_{2}\right)$ levels were markedly elevated (2,368 pg/ml), with FSH: 15.7 $\mathrm{mIU} / \mathrm{ml}$ (normal range for follicular phase 2.5-10.2 $\mathrm{mIU} / \mathrm{ml}$ ), LH: $4.9 \mathrm{mIU} / \mathrm{ml}$ (normal range for follicular phase $0.5-16.9 \mathrm{mIU} / \mathrm{ml}$ ) and prolactin (PRL) was also elevated 4,091 mIU/l (193 ng/ml) (normal range for $\mathrm{PRL}<23.3 \mathrm{ng} / \mathrm{ml}$ ). Estrogen levels were compatible with ovarian hyperstimulation, which was confirmed by pelvic ultrasonography that demonstrated enlarged ovaries with multiple cysts ranging from 3 to $4.5 \mathrm{~cm}$ in maximal diameter and endometrium thickness of $7 \mathrm{~mm}$ (Figure 1a). Magnetic resonance imaging (MRI) of the hypothalamic-pituitary region revealed a macroadenoma (maximal diameter $28 \times 26 \times 16 \mathrm{~mm}$ ) with suprasellar extension and optic chiasm compression. Assessment of anterior pituitary function was consistent with GH deficiency; adrenal and thyroid function was normal.

In view of the optic chiasm compression immediate transsphenoidal resection was performed. Immunohistochemical staining was positive mainly for $\beta$-FSH and to a lesser extent $\alpha-\mathrm{SU}$ and $\beta-\mathrm{LH}$ and negative for GH, PRL, ACTH and $\beta$-TSH. Ki-67 index was estimated approximately $1.5 \%$. Her post-operative course was uneventful and subsequently she resumed normal menstruation. Two months post-operatively and on day 6 of the follicular phase FSH was 3.5 $\mathrm{mIU} / \mathrm{ml}, \mathrm{LH}: 0.7 \mathrm{mIU} / \mathrm{ml}$ and $\mathrm{E}_{2}: 175 \mathrm{pg} / \mathrm{ml}$ (normal range from $2^{\text {nd }}$ to $9^{\text {th }}$ day: $10-50 \mathrm{pg} / \mathrm{ml}$ ) (Figure $2 \mathrm{a}$ ), while PRL was $685 \mathrm{mIU} / \mathrm{l}(32.3 \mathrm{ng} / \mathrm{ml})$. Transvaginal ultrasonography showed partial regression of the ovarian cysts, ranging between 2 to $2.8 \mathrm{~cm}$ longitudinal

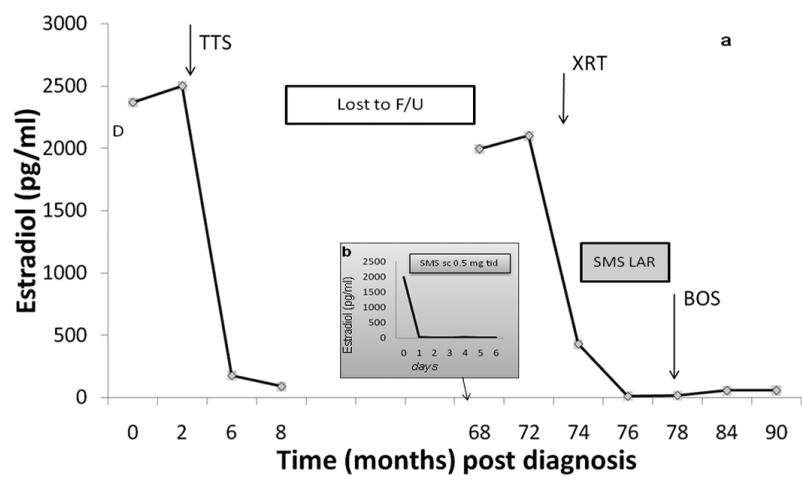

Figure 2. Estradiol $\left(\mathrm{E}_{2}\right)$ levels at diagnosis and during followup (a). Estradiol $\left(E_{2}\right)$ levels during short-term treatment with $500 \mu \mathrm{g}$ octreotide subcutaneously three times daily for six serial days (b). Arrows indicate treatment modalities. D: diagnosis; TSS: transsphenoidal surgery; SMS sc $0.5 \mathrm{mg}$ tid: Sandostatin $0.5 \mathrm{mg}$ subcutaneously three times daily; XRT: conventional radiation therapy; SMS LAR: Sandostatin LAR $30 \mathrm{mg}$. a

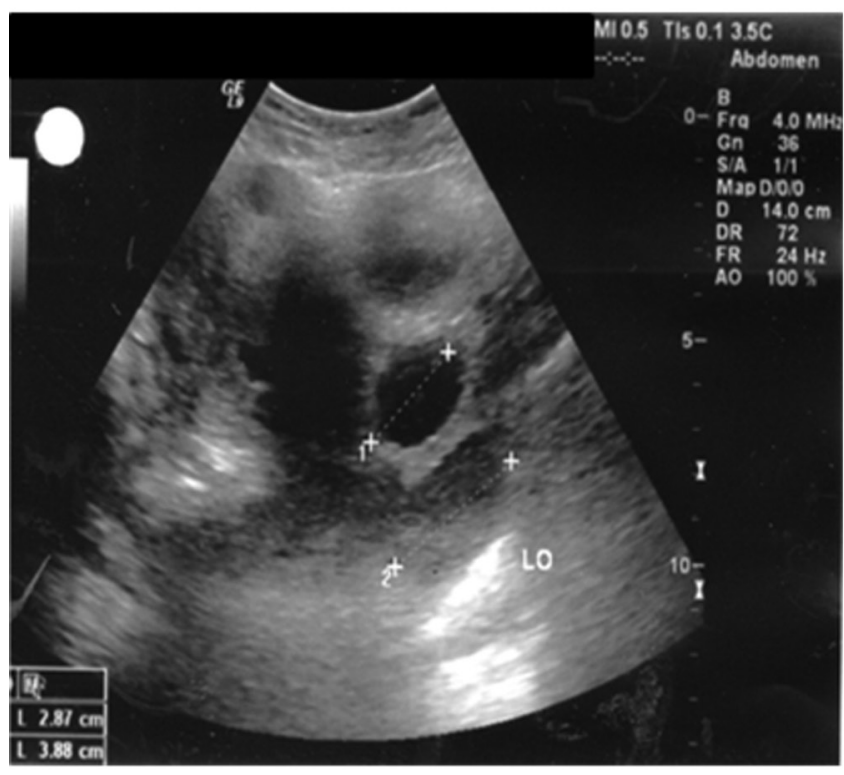

b

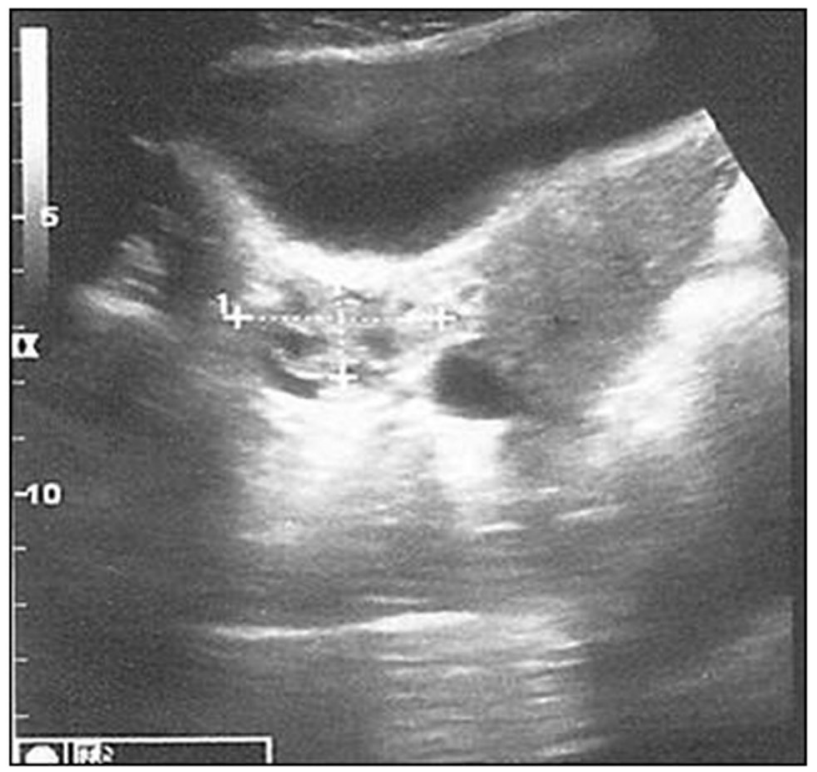

Figure 1. Pelvic ultrasound at diagnosis (a), and during Sandostatin LAR $30 \mathrm{mg}$ treatment (b). 
diameter and normal endometrial lining of around $3.5 \mathrm{~mm}$. Four months post-operatively on day 23 of her menstrual cycle FSH was $8.3 \mathrm{mIU} / \mathrm{ml}$ (normal range for lutear phase $1.5-9.1 \mathrm{mIU} / \mathrm{ml}$ ), LH $3.7 \mathrm{mIU} /$ $\mathrm{ml}$ (normal range for lutear phase $0.5-16.9 \mathrm{mIU} / \mathrm{ml}$ ), $\mathrm{E} 2: 87.87 \mathrm{pg} / \mathrm{ml}$ (normal range between $20^{\text {th }}$ and $25^{\text {th }}$ day: $60-260 \mathrm{pg} / \mathrm{ml}$ ) and PRL was normal as well at $365 \mathrm{mIU} / \mathrm{l}(17.2 \mathrm{ng} / \mathrm{ml})$. Ovaries were normal on ultrasonography with complete cysts regression but MRI revealed a small solid residual tumor of $10 \mathrm{~mm}$ maximal diameter without optic chiasm compression.

The patient was then lost to follow-up for four years. She returned to our center with irregular vaginal spotting. Curettage performed by her $\mathrm{OB} /$ GYN revealed glandular endometrial hyperplasia. Transabdominal ultrasonography revealed again ovarian hyperstimulation. $E_{2}$ levels were $1,994 \mathrm{pg} / \mathrm{ml}$ with inappropriately elevated gonadotropins (FSH: $14.1 \mathrm{mIU} / \mathrm{ml}$ and LH: $4.8 \mathrm{mIU} / \mathrm{ml}$ ). Recurrence was further confirmed by MRI, which showed a solid intra-sellar mass with increased dimensions (maximal diameter $19 \times 14 \times 13 \mathrm{~mm}$ ), almost twice the size of the residual post-TSS remnant.

In an effort to control the continuous estrogen secretion due to the autonomous gonadotropin secretion from the pituitary adenoma, and the inappropriate exposure to estrogen of breast and endometrium, short-term treatment with $500 \mu \mathrm{g}$ octreotide subcutaneously three times daily (Sandostatin, Novartis, Basel, Switzerland) was initiated. $E_{2}$ levels were evaluated the following day and for six serial days afterwards. $\mathrm{E}_{2}$ levels dramatically decreased from $1,994 \mathrm{pg} / \mathrm{ml}$ to 14 $\mathrm{pg} / \mathrm{ml}$ and vaginal bleeding gradually resolved (Figure $2 b$ ). In order to achieve better compliance, treatment with long-acting octreotide (Sandostatin LAR $30 \mathrm{mg}$, Novartis, Basel, Switzerland) was initiated. For longterm control of the tumor she received conventional irradiation with $4676 \mathrm{cGy}$. Two months later estradiol levels decreased by $97.8 \%$ (from $429 \mathrm{pg} / \mathrm{ml}$ to $9 \mathrm{pg}$ / $\mathrm{ml}$ ) (Figure 2a) remaining within normal levels, and the ovaries regressed to normal (ovarian volume 6 $\mathrm{ml}$ left and $8 \mathrm{ml}$ right, Figure 1b). Meanwhile, due to suspicious features on ultrasonography involving a thickened and heterogeneous uteral wall, hysterectomy and bilateral salpingoophorectomy was suggested and performed by her OB/GYN. The pathology report was negative for malignancy. Sandostatin LAR treat- ment was discontinued as ovarian hyperstimulation syndrome was no longer an issue. After two months off treatment, $\mathrm{LH}$ was $14.9 \mathrm{mIU} / \mathrm{ml}$, FSH was 41.2 $\mathrm{mIU} / \mathrm{ml}$, consistent with menopause and E2 was 16pg/ $\mathrm{ml}$. The patient was re-evaluated six months and one year post salpingoophorectomy; FSH was 28.5 and $23.2 \mathrm{mIU} / \mathrm{ml}, \mathrm{LH} 9$ and $6.4 \mathrm{mIU} / \mathrm{ml}$ and $\mathrm{E}_{2} 55$ and $56.5 \mathrm{pg} / \mathrm{ml}$, respectively. PRL was 27.4 and $15.7 \mathrm{ng} /$ $\mathrm{ml}(581$ and $333 \mathrm{mIU} / \mathrm{l})$, respectively, and tumor size was unchanged compared to the size at recurrence $(19 \times 14 \times 13 \mathrm{~mm})$.

\section{DISCUSSION}

Few cases of OHSS associated with gonadotroph pituitary adenomas have been reported so far. ${ }^{3,4,6}$ Regression of the enlarged multicystic ovaries and restoration of the regular menstrual cycles can be achieved by excising the pituitary adenoma. ${ }^{3}$ However, persistence or recurrence of these tumors is common with concomitant chronic exposure of the patient to extremely high estrogen levels.

Pituitary irradiation is an alternative treatment option but its effect on the control of tumor mass and hormonal hypersecretion appear several years after treatment. ${ }^{1}$ Experience in immediate acting medical management of these tumors is limited. Dopamine agonists such as bromocriptine and cabergoline have proven to be effective in reducing estradiol levels and decreasing ovarian size, ${ }^{7,8}$ but tumor reduction very occasionally occurs, usually under high doses of bromocriptine. ${ }^{9} \mathrm{GnRH}$ analogs are not effective and may induce a paradoxical increase in gonadotropin secretion, ${ }^{7,10}$ leading to deterioration of OHSS.

In vitro data suggest that gonadotrophin-secreting pituitary adenomas may be sensitive to somatostatin analogs. ${ }^{11}$ Indeed, long-acting somatostatin analogs have been used with some success in hormonal hypersecretion. ${ }^{11}$ In addition, only a few cases of significant tumor size shrinkage after subcutaneous octreotide acetate administration have been reported. ${ }^{12,13}$ In our patient, short-term treatment with subcutaneous somatostatin analog led to an immediate decrease of estrogen levels within the normal range. A sustained effect was also observed on subsequent treatment with long-acting somatostatin analog resulting in normalization of the ovarian size and recovery from 
the OHSS. In this case, we used a high dose sandostatin LAR treatment as we aimed for the strongest effect as quickly as possible. It should be noted that the patient underwent pituitary irradiation almost simultaneously with the initiation of Sandostatin LAR treatment. However, it is highly unlikely that such an immediate drop of estrogen levels is a result of the control of autonomous gonadotropin secretion by the irradiation. On the contrary, irradiation effect on gonadotropinomas mass and secretion, if any, occurs after several years. ${ }^{14}$ Thus, somatostatin analog may be a reasonable option in selected patients with clinically functioning gonadotroph adenomas in addition to the other treatment modalities, as pituitary surgery and irradiation.

In conclusion, we report a case of recurrent OHSS due to a gonadotropin releasing pituitary tumor successfully responding to octreotide treatment which supports its use as a treatment modality for future cases.

\section{Conflict of interest}

The authors declare that they have no conflict of interest.

\section{REFERENCES}

1. Chaidarun SS, Klibanski A, 2002 Gonadotropinomas. Semin Reprod Med 20: 339-348.

2. Katznelson L, Alexander JM, Klibanski A, 1993 Clinical review 45: Clinically nonfunctioning pituitary adenomas. J Clin Endocrinol Metab 76: 1089-1094.

3. Kihara M, Sugita T, Nagai Y, Saeki N, Tatsuno I, Seki K, 2006 Ovarian hyperstimulation caused by gonadotroph cell adenoma: a case report and review of the literature. Gynecol Endocrinol 22: 110-113.

4. Gryngarten MG, Braslavsky D, Ballerini MG, Ledesma J, Ropelato MG, Escobar ME, 2010 Spontaneous ovarian hyperstimulation syndrome caused by a folliclestimulating hormone-secreting pituitary macroadenoma in an early pubertal girl. Horm Res Paediatr 7: 293-298.

5. Dahlqvist P, Koskinen LO, Brännström T, Hägg E, 2010 Testicular enlargement in a patient with a FSH-secreting pituitary adenoma. Endocrine 37: 289-290.

6. Cooper O, Geller JL, Melmed S, 2008 Ovarian hyperstimulation syndrome caused by an FSH-secreting pituitary adenoma. Nat Clin Endocrinol Metab 4: 234-238.

7. Murata Y, Ando H, Nagasaka T, et al, 2003 Successful pregnancy after bromocriptine therapy in an anovulatory woman complicated with ovarian hyperstimulation caused by follicle-stimulating hormone producing plurihormonal pituitary microadenoma. J Clin Endocrinol Metab 88: 1988-1993.

8. Knoepfelmacher M, Danilovic DL, Rosa Nasser RH, Mendonca BB, 2006 Effectiveness of treating ovarian hyperstimulation syndrome with cabergolide in two patients with gonadotropin-producing pituitary adenomas. Fertil Steril 86: 719.e15-18.

9. Yamakita N, Komaki T, Murai T, Kawamura S, 1999 Reduction of plasma gonadotropin levels and pituitary tumor size by treatment with bromocriptine in one patient with gonadotropinoma. Intern Med 38: 266-271.

10. Christine-Maitre S, Rongieres-Bertrand C, Kottler ML, et al, 1998 A spontaneous and severe hyperstimulation of the ovaries revealing a gonadotroph adenoma. J Clin Endocrinol Metab 83: 3450-3453.

11. Saveanu A, Morange-Ramos I, Gunz G, Dufour H, Enjalbert A, Jaquet P, 2001 A luteinizing hormone-, alpha- subunit- and prolactin- secreting pituitary adenoma responsive to somatostatin analogs: in vivo and in vitro studies. Eur J Endocrinol 145: 35-41.

12. Sy RA, Bernstein R, Chynn KY, Kourides IA, 1992 Reduction in size of a thyrotropin- and gonadotropinsecreting pituitary adenoma treated with octreotide acetate (somatostatin analog). J Clin Endocrinol Metab 74: 690-694.

13. Warnet A, Harris AG, Renard E, Martin D, James-Deidier A, Chaumet-Riffaud P, 1997 A prospective multicenter trial of octreotide in 24 patients with visual defects caused by non-functioning and gonadotropin-secreting pituitary adenomas. French Multicenter Octreotide Study Group. Neurosurgery 41: 786-795.

14. Kanner AA, Corn BW, Greenman Y, 2009 Radiotherapy of nonfunctioning and gonadotroph adenomas. Pituitary 12: $15-22$. 